\title{
Religion and Religious Doubt: Predictors of Psychological Distress in Emerging Adults
}

\author{
John W. Lace \\ Graduate Student, Saint Louis University, Missouri, USA \\ Corresponding Author-lacejw@slu.edu \\ Paul J. Handal \\ Professor, Saint Louis University, Missouri, USA \\ handalpj@ slu.edu
}

\begin{abstract}
The present study examined the predictive effect of religious dimensions and religious doubt on psychological distress in emerging adult males and females. Participants included 637 (440 females) individuals from a religiously affiliated, Midwestern university. Data were collected online, and $66 \%$ of participants received extra credit for participating. Respondents completed the Personal Religious Inventory to assess their selfreport of dimensions of religion; a single-item measure of religious doubt to understand the degree of certainty or doubt about their religious beliefs; and the Langner Symptom Survey to assess the severity of reported psychological distress. Results indicated that dimensions of religion and religious doubt significantly predicted psychological distress only in emerging adult females. Religion and religious doubt were not predictive of psychological distress for emerging adult males. The present study suggests the relationships among religious dimensions, religious doubt, and psychological distress may be unique for men and women and discusses possible reasons.
\end{abstract}

Keywords: religious doubt, psychological distress, emerging adults, sex differences

\section{Introduction}

Religion, an inherently multidimensional construct, includes "beliefs, behaviors, rituals, and ceremonies that may be held or practiced in private or public settings . . . developed over time within a community" (Koenig, 2012, p. 2-3). Thus, religion is comprised of many facets, each of which may be relevant to individuals in different manners, and cannot be assessed by unidimensional tools. Religion and its dimensions (e.g., prayer, attendance of religious services) have a mixed relationship with mental health and psychological distress (Weber \& Pargament, 2014). Some argue the protective nature of religion provides social support, interpersonal connectedness, and existential explanations for experiences (Idler, 1987). Others argue that its emphasis on sin and guilt may contribute to the development of psychopathology (Freud, Stachey, \& Gay 1989).

However, early and recent meta-analyses suggested that religion likely relates positively to mental health outcomes. For example, Bergin's (1983) meta-analysis reported a mean correlation of $r=.09$ between religiosity and psychological health, suggesting that increased overall religious involvement related to beneficial mental health. Hackney and Sanders (2003) similarly reported a low, although positive, link between religion and psychological health $(r$ $=.10$ ). The $r$ values reported in these studies (Bergin, 1983; Hackney \& Sanders, 2003) suggest that increased religious involvement significantly, although perhaps weakly, relates to 
improved mental health outcomes and better overall psychological functioning. Furthermore, Koenig, King, and Carson (2012) and Koenig (2012) recently noted that religion generally is associated with greater wellbeing and better mental health. In all, it appears that the preponderance of literature on the topic supports a "salutary relationship" (Hackney \& Sanders, 2003, p. 51) with mental health.

Religious doubt may be defined as "a feeling of uncertainty toward, and a questioning of, religious teachings and beliefs (Hunsberger, McKenzie, Pratt, \& Pancer, 1993, p. 28). Theoretically, religious doubt may have a complex relationship with religion.In regard to religious doubt and religion, some argue that doubt is an intrinsic element of religious life and may, in fact, have beneficial results (Batson, Schoenrade, \& Ventis, 1993; Kapleau, 1980). Respected theologians have argued that "faith includes [emphasis added] the doubt about itself," (Tillich, 2001, p. 119), and doubt and faith are not mutually exclusive. However, scientific literature suggests religious doubt is related to lower church attendance (Hunsberger, Pratt, \& Pancer, 2002), decreased interest in religion and intrinsic religiosity (Watson, Morris, Hood, Milliron, \& Stutz, 1998), and diminished spiritual wellbeing (Klaassen \& McDonald, 2002). Thus, according to scientific research, religious doubt appears to relate negatively to religiosity.

In regard to its relationship to mental health, religious doubt has a generally negative relationship to mental health, as much research broadly supports an inverse link between religious doubt and poorer mental health. For example, Ellison (1991) reported that religious doubt had an overall negative impact on personal wellbeing, and Krause (2006) reported that religious doubt is associated with decreased optimism, self-esteem, and overall life satisfaction over time. Krause and Wulff (2004) noted that those who doubt their faith more are less satisfied with their health and suffer from greater depression than those with few doubts regarding their religion. Galek, Krause, Ellison, Kudler, and Flannelly (2008) reported significant effects of religious doubt on various measures of mental distress, including those assessing for depression, interpersonal sensitivity, generalized anxiety, paranoia, hostility, and obsessive-compulsive spectrum symptoms. In all, there appears a general relationship between religious doubt and poorer mental health or other psychological outcomes.

Recent empirical research has shifted focus to understanding relationships among religion, its doubts, and mental health in emerging adults, as this population may be at a higher risk of developing psychopathology compared to adults and younger adolescents (Arnett, 2000; Schulenberg \& Zarrett, 2006). Emerging adulthood, the age between approximately 18 and 25 (Arnett, 2000), is when most mental health problems have their first onset (Kessler et al., 2005). Notably, results from a recent survey of 763 college students showed that over half of these participants suffered from at least one mental health problem at baseline and after two years (Zivin, Eisenberg, Gollust, \& Golberstein, 2009). Relatedly, Creech and colleagues (2013) reported a decrease in religious attendance and non-religious attendance over one's academic career. In all, emerging adults remain an important population for psychological research.

Within adolescence and emerging adulthood, the relationship between religious doubt and psychological distress may be especially salient. High school and university students with high levels of religious belief demonstrated a significant, positive correlation between religious doubt and both anxious and depressive symptoms (Kézdy, Martos, Boland, \& Horváth-Szabó, 2011). Krause, Ingersoll-Dayton, Ellison, and Wulff (1999) suggested that religious doubt is associated with greater depressed affect, and that this effect is strongest in 
20-year-olds compared to those of older ages perhaps due to the lack of experience in dealing with religious doubt and reconciling it with one's beliefs and mental health. Similarly, Galek and colleagues (2008) reported that for those at age 29.5, the link between religious doubt and outcome measures of depression, anxiety, interpersonal sensitivity, obsessive-compulsive symptoms, paranoia and hostility is significant; for individuals at age 69.5, however, the relationship between religious doubt and psychological distress "has declined substantially" (Galek et al., 2008, p. 20). Thus, it may be that religious doubt has notable, clinical consequences for younger people.

In all, religion and religious doubt have both been associated with mental health outcomes. The present study seeks to contribute to the literature relating religion, religious doubt, and psychological distress. This research was designed to determine if religious doubt adds significantly to the prediction of psychological distress after accounting for variance explained by religious dimensions. It was predicted that religious doubt would account for a statistically significant amount of variance of psychological distress above and beyond that which was significantly accounted for by religion.

\section{Methods}

\section{Participants}

Participants were recruited from undergraduate courses at a religiously affiliated, Midwestern university. The sample consisted of 637 individuals, $(M$ age $=19.37, S D=1.31)$, with 197 males $(M$ age $=19.52, S D=1.38)$ and 440 females $(M$ age $=19.30, S D=1.27)$. Ages ranged from 18 to 25 with no significant difference in age between males and females $(p=.07)$.

Participants were predominantly Caucasian (75.3\%), 9.6\% identified as Asian or AsianAmerican, 3.9\% identified as South Asian or Indian-American, 3.8\% identified as Multiracial or Multi-ethnic, $2.8 \%$ identified as Black or African-American, 2.5\% identified as Hispanic or Latina/Latino, and $1.6 \%$ identified as Middle Eastern or Arab-American. One participant each identified as Native American or Native Alaskan, Hawaiian or Pacific Islander, and "Greek."

Participants were from a variety of religious backgrounds, with most identifying as Catholic (56.5\%). Others identified as Protestant (10.0\%), Non-denominational Christian (8.8\%), Agnostic (6.3\%), Atheist (3.6\%), Hindu (3.6\%), Muslim (3.3\%), Buddhist (0.5\%) and Jewish $(0.2 \%)$. The remaining $7.2 \%$ identified as "Other." Participants reported a range of family annual income from less than $\$ 40,000(6.0 \%)$ to greater than $\$ 160,000$ (23.9\%), with the median reported annual family income being between $\$ 100,000$ and $\$ 120,000$. Eight individuals did not report annual family income. Their datasets were complete for all other variables, thus they were included in the analysis.

\section{Measures}

Religion. Due to the multidimensional nature of religion that includes beleifs, practices, rituals and ceremonies (Koenig, 2012), a measure that assesses several facets of religion was chosen for use in the present study. The Personal Religious Inventory (PRI; Lipsmeyer, 1984) is a widely used measure of religiosity (Creech et al., 2013; Handal\& Lace, in press; Ross et al., 2009). It contains 45 -items that measure nine dimensions of religion. These dimensions 
include Personal Prayer (PRP), Ritual Attendance (RA), Non-ritual, Church-related Activities (NRA), Belief in God (BLF), Closeness to God (CLS), Belief in Afterlife (AFT), Religion and Social/Moral Issues (RSM), Religion and Personal Ideologies and Philosophy (IDEO), and Integration of Religion into One's Life (INT).

Psychometric properties of the PRI are reported extensively by Lipsmeyer (1984). PRI subscales have demonstrated excellent test-retest reliability over a one-week period (.83 to .97; Lipsmeyer, 1984). PRI subscales have shown high construct validity as those holding religious positions (e.g., clergymen, nuns) reported significantly higher scores than those in a sample of the general population, and atheists, agnostics, and those with no religious preference scored significantly lower than those belonging to major religious groups (Lipsmeyer, 1984). The INT scale has been purported to be the best single measure of religion (Lipsmeyer, 1984; Ross et al., 2009) due to it having the highest correlations to all other PRI subscales in its standardization sample (Lipsmeyer, 1984). Other validity for PRI subscales has been shown with relation to psychological distress in samples of emerging adults (Low \&Handal, 1995), adults (Crawford et al., 1989), and adolescents (Mosher \&Handal, 1997)

Religious Doubt. A single item measuring the extent to which participants doubt their religion was included in the present study. The item was worded as follows: "Do you ever doubt your religion/faith/beliefs?" The item was accompanied by a 7-point Likert scale with anchor points of (1) as "Very Doubtful," (4) as "Neutral," and (7) as "Very Certain," with higher ratings reflecting greater confidence and certainty in one's religion, beliefs, or faith. In the present sample, this item demonstrated a moderate, positive correlation with the INT scale of the PRI, $r(637)=.49, p<.01$, and the CLS scale of the PRI, $r(637)=.46, p<.01$. These significant, moderate correlations suggest that higher ratings of religious integration and subjective closeness to God were associated with higher certainty in one's beliefs, and thus acceptable concurrent validity for the item assessing religious doubt.

Psychological Distress. The Langner Symptom Survey (LSS; Langner, 1962) is a widely used epidemiological measure of psychological distress and need for treatment (Dooley \& Catalano, 1979; Handal\& Lace, in press; Ross et al., 2009). It assesses difficulties related to sleep, symptoms of somatization, subjective feelings of loneliness and low spirit, cognitive difficulties, and anxious and depressive symptomatology. Examples of items on the LSS include: "I have personal worries that get me down physically (make me physically ill)," "Do you feel somewhat apart even among friends (apart, isolated, alone)?" and "I have periods of such great restlessness that I cannot sit long in a chair (cannot sit still very long)." Each item is scored dichotomously with a score of 0 or 1 , indicative of either the absence or endorsement of a target symptom, respectively. LSS scores range from 0 to 22, and higher scores represent greater psychological distress and need for treatment.

The LSS has a reported overall internal consistency (Cronbach's alpha) of 0.80 (Ross et al., 2009), and has demonstrated good psychometric properties for use in epidemiological research as reported by Cochrane (1980). The LSS has demonstrated discriminant validity in accurately identifying more than $84 \%$ of adult inpatients and outpatients from healthy controls (Langner, 1962), and has demonstrated an overall identification rate of $79 \%$ in an adolescent population (Handal, Gist, Gilner, \&Searight, 1993). Langner (1962) and Handal and colleagues (1993) reported a validated cutoff score of 4 or higher to denote clinically significant psychological distress and need for treatment in adults and adolescents, and a validated cutoff score of 5 for use with emerging adults (Handal, Peri, \&Pashak, 2014). 
Demographic Questionnaire. Participants completed a 22-item demographic questionnaire. These items gathered information about participants' age, race/ethnicity, sex, religious affiliation, college living arrangement, volunteer and work positions, and psychological service history utilization.

\section{Procedures}

Ethical approval was obtained by the participating university before data collection began. Participants were part of a larger study and were recruited from undergraduate psychology classes. Some classes (approximately 66\%) offered class credit for participation, while the other classes were not offered incentives for participation. Participants accessed the study via SONA, a university-approved research recruitment program, or through a link provided to them by professors who helped with recruitment. After accessing the study, they were directed to a link to the Qualtrics site hosting the survey. Participants first answered the demographic questionnaire and the item of religious doubt. Next, participants progressed through the PRI followed by the LSS. Participants were encouraged to complete all sections in order, but were able to progress through the questionnaires at will. Participants were allowed to skip items or discontinue as desired. Only participants with complete data for these measures were included for analyses.

\section{Results}

The distribution of the LSS in the present sample was positively skewed and notably leptokurtic (Bulmer, 1979). In accordance with proper statistical practices (Field, 2013; Habibzadeh, 2013), a nonparametric, Mann-Whitney U test was performed to determine whether or not the distribution of LSS scores was equivalent for males and females. Results revealed a significant Mann-Whitney U test, $U=38,580.00, p=.026, r=.09$, indicating that the distribution of LSS scores was not equivalent for males and females. As such, the sample was separated by sex for analysis.

In order to determine the amount of variance of LSS scores accounted for by variables measuring religion and religious doubt, hierarchical multiple regressions were performed in the samples of males and females. For the first step of each regression, the nine scales from the PRI were included. This served to maintain consistency in predictors between male and female samples while accounting for as much unique variance by religious dimensions as possible. The second step of each regression added the measure of religious doubt. Table 1 displays coefficients of each variable at each step for the regressions for both males and females, respectively.

For males, the model with only PRI scales as predictors revealed that R was not statistically different from zero, $F(9,187)=1.75, p=.082, R^{2}=.077$. Adding the measure of doubt to the model did not result in a statistically significant change in the model, $F$-Change $(1,186)=$ $1.04, p=.309, R^{2}$ Change $=.005$. The final model with PRI scales and religious doubt was not statistically significantly different from zero, $F(10,186)=1.68, p=.089, R^{2}=.083$. These results indicate that neither the model with PRI scales only nor the model with PRI scales and religious doubt accounted for a statistically significant amount of the variance in LSS scores for males.

For females, the model with the PRI scales as predictors revealed that $\mathrm{R}$ was statistically different from zero, $F(9,430)=4.53, p<.001, R^{2}=.087$. The IDEO, RSM, INT, and CLS scales of the PRI emerged as significant individual predictors of the LSS in the first step of 
the regression. Increased IDEO scores related to increased LSS scores, and increased RSM, INT, and CLS scores related to decreased LSS scores for females. Adding the measure of religious doubt to the model for females resulted in a statistically significant change in the model, F-Change $(1,429)=4.97, \mathrm{p}=.026, \mathrm{R} 2$ Change $=.010$, indicating that the second step accounted for an additional $1 \%$ of the variance in LSS scores. The final model with PRI scales and religious doubt was statistically significantly different from zero, $F(10,429)=$ $4.61, p<.001, R^{2}=.097$, indicating the final model accounted for $9.7 \%$ of the variance in LSS scores. In the final model, the PRP, IDEO, and INT scales from the PRI and the measure of religious doubt emerged as significant individual predictors of the LSS, as did religious doubt. This suggests that, in the final model, increased PRP, IDEO, and religious doubt scores related to increased LSS scores, and increased INT scores related to decreasedLSS scores. Overall, these results indicate that the PRI scales accounted for a statistically significant amount of variance in LSS scores for females, and that adding the measure of religious doubt accounted for additional statistically significant variance.

Table 1

Coefficients from hierarchical multiple regression analysis for males and females

\begin{tabular}{lcccccccc}
\hline & \multicolumn{3}{c}{ Males } & \multicolumn{2}{c}{ Females } \\
\hline Variables & B & $\beta$ & B & $\beta$ & B & $\beta$ & B & $\beta$ \\
\hline PRP & .10 & .18 & .01 & .17 & .10 & .18 & $.10^{*}$ & .19 \\
RA & $<.01$ & .01 & .01 & .02 & -.05 & -.09 & -.04 & -.08 \\
NRA & .01 & .01 & $<.01$ & $<.01$ & .03 & .04 & .03 & .04 \\
IDEO & -.04 & -.03 & -.04 & -.03 & $.25 * *$ & .17 & $.28 *$ & .20 \\
RSM & -.06 & -.11 & -.06 & -.10 & $-.06 *$ & -.12 & -.05 & -.10 \\
INT & .01 & .04 & .01 & .06 & $-.04 *$ & -.25 & $-.04 *$ & -.25 \\
BLF & .14 & .07 & .10 & .05 & .10 & .04 & .11 & .05 \\
AFT & -.20 & -.08 & -.13 & -.05 & -.16 & -.06 & -.13 & -.05 \\
CLS & $-.99 * *$ & -.34 & $-.94 * *$ & -.33 & $-.04 *$ & -.17 & -.43 & -.15 \\
Rel. Doubt & -- & -- & -.17 & -.09 & -- & -- & $-.25 *$ & -.13 \\
Constant & $6.84 * *$ & -- & $6.95 * *$ & -- & $7.03 * *$ & -- & $7.04 * *$ & -- \\
\hline
\end{tabular}

Note: $* p<.05, * * p<.01$. PRP $=$ Personal Prayer; RA $=$ Ritual Attendance; NRA $=$ NonRitual Attendance; IDEO = Ideology; RSM = Religion/Social-Moral; INT = Integration; BLF $=$ Belief in God; AFT $=$ Belief in Afterlife; CLS $=$ Closeness to God; Rel. Doubt $=$ Religious Doubt. 


\section{Discussion}

The objective of this study was to determine the predictive effect of religious dimensions and religious doubt on psychological distress in emerging adults. Religion and religious doubt did not emerge as significant predictors of psychological distress in emerging adult males, whereas these variables did emerge as significant predictors of psychological distress in emerging adult females. Dimensions of religiosity and religious doubt accounted for nearly $10 \%$ of the variance in psychological distress in emerging adult females.

The present study offers two primary conclusions. First, religion accounted for a significant amount of variance in psychological distress for emerging adult females. Specifically, the final regression model demonstrated that personal prayer (PRP), the relationship between religion and one's personal philosophy (IDEO), and the degree to which one's religion influences her mood, cognition, and behavior (INT) accounted for $4 \%$ of the variance in females' psychological distress. It may be that these facets of religiosity (i.e., prayer, religion and personal philosophy, and overall integration) are the most salient aspects of religiosity related to mental health for women as they emerged as the strongest individual predictors among all nine included religious dimensions. The remaining scales measuring other dimensions of religion, while not each individually statistically significant at $p<.05$, accounted for another $4.7 \%$ of the variance in females' psychological distress. Thus, religious dimensions accounted for a significant amount of psychological distress in emerging adult females.

Second, a single-item measure of religious doubt accounted for an additional $1 \%$ of the overall variance in psychological distress reported by emerging adult females. That is, above and beyond the variance in psychological distress accounted for by emerging adult females' religious dimensions, the extent to which they experience doubt of religious beliefs or faith predicted additional psychological distress. These findings partially supported the hypothesis of the present study in that the predicted effect was observed only within emerging adult females. Notably, these findings support an overall, emerging trend of sex differences in the research of religion and psychological distress in emerging adults. Previous research has suggested that women are more likely to report higher levels of religion than men (Gallup \& Lindsay, 1999), and more recent literature has reported this finding in emerging adults, as well (Handal \& Lace, in press).

Of note, the conclusion that neither religion nor religious doubt significantly predicted mental health for emerging adult males should be viewed with caution. First, both steps of the hierarchical regression analysis for males approached, but did not achieve, statistical significant ( $p=.082, p=.089$, respectively). It is possible that with a larger sample of men, statistical significance might have been reached (Cohen, 1992). However, even if that were to occur, it still appears that the salience of the relationships among religion, religious doubt, and psychological distress are not as strong as those among women.

In understanding why such a pattern between men and women emerges, possible explanations may be considered. It may be that women who are more religious and experience less religious doubt are better able to regulate their emotions (Watterson \&Giesler, 2012) and may be better able to internally minimize experienced psychological distress. It may be that women who doubt their religion are more likely internalize their doubt. Such increased internalized religious doubt may be perceived as incongruent with one's religious teaching, 
and therefore function as a stressor in and of itself (Ellison \& Lee, 2010), thus contributing to greater psychological distress. This belief may be more prominent for women and thus more strongly influence outcomes of psychological distress.

Perhaps women who experience religious doubt are more likely to separate from the social support and collaborative coping mechanisms offered by religion (Idler, 1987) and be less connected to and more reluctant to share their feeligns with their religious peers. Such a loss of social connectivity and support may result in a decrease in social support and method existential explanation for difficulties arising in life. It would follow that women who experience psychological distress may distance themselves from religious involvement, and subsequently experience greater levels of religious doubt, thereby increasing risk factors for developing distress.

However, other work has linked self-reported religiosity to increased social desirability and impression management (e.g., Gillings \& Joseph, 1996; Leak \& Fish, 1989), which may relate to the underreporting of psychopathological symptoms. It may be a phenomenon that is possibly stronger for women than for men. Future research may consider mediating and moderating variables in explaining this connection. Also, these conclusions suggest screening for sex differences is important in future research to prevent spurious conclusions that may be generalizable for one sex but not the other.

More broadly beyond statistically significant results, the findings in the present study support clinically significant conclusions for mental health practitioners, clergy members, religious teachers, paraprofessionals, or other individuals who may interact with the aspects of religion, doubt, and psychological distress regularly. These professionals should be aware, not only, of an individual's religious beliefs and practice, but also of religious doubt that may be present. The presence of doubt within religious conviction has an additive effect on poorer mental health above and beyond one's religious dimensions. In short, practitioners may choose to consistently assess for and be mindful of religion and religious doubt in a clinical context (see Koenig, 2004; Koenig 2012). It would be helpful if practitioners understand the nuanced relationship between religion and mental health, which may be protective or deleterious (e.g., Ellison \& Lee, 2010; Weber \& Pargament, 2014). It would be helpful for practitioners to be aware of the role of doubt, questioning, and growth seeking within religious individuals and strive to promote clients' wellbeing.

\section{Conclusion}

\section{Limitations and Future Directions}

Limitations within the present study involve participants' membership at a religiously affiliated university in the Midwestern United States. Additionally, this was a predominantly Christian (75.3\%) sample. Further, participants were mostly White $(75.3 \%)$ with relatively fewer students of African (2.8\%) or Latino (2.6\%) descent. The sample appeared relatively affluent as compared to the general American population, as the median annual family income reported by participants in this sample was greater than $\$ 100,000$. Future research should seek to expand the geographic and demographic generalizability of related findings, and ensure the recruitment of racially and socioeconomically representative samples.

Another limitation involves the present study's research tools. The use of a single-item measure of religious doubt may be a limiting factor in the generalizability of these findings 
and future research should consider other measures of assessing religious doubt. Additionally, the present study's methodology utilized a monomethod approach as only self-reported data were gathered and analyzed. Future research may seek to involve informants in the report of psychological distress and observational or objective data in regards to religiosity (e.g., frequency of church attendance, hours spent in prayer) gathered by researchers.

\section{References}

Arnett, J. J. (2000). Emerging adulthood: A theory of development from the late teens through the twenties. American Psychologist, 55(5), 469-480. doi:10.1037/0003-066x.55.5.469

Batson, C.D., Schoenrade, P.A., \&Ventis, W.L. (1993). Religion and the individual: A socialpsychological perspective. New York: Oxford University Press.

Bergin, A. E. (1983). Religiosity and mental health: A critical reevaluation and meta-analysis. Professional Psychology: Research and Practice, 14(2), 170-184. doi:10.1037/07357028.14.2.170

Bulmer, M. G. (1979) Principles of Statistics. Dover. New York.

Cochrane, R. (1980). A comparative evaluation of the symptom rating test and the Langner 22-item index for use in epidemiological surveys. Psychological Medicine, 10(01), 115124. doi:10.1017/s0033291700039647

Cohen, J. (1992). Statistical Power Analysis.Current Directions in Psychological Science, 1(3), 98-101. doi:10.1111/1467-8721.ep10768783

Creech, C., Handal, P., Worley, S., Pashak, T., Perez, E. \& Caver, L. (2013). Changing Trends in Ritual Attendance and Spirituality throughout the College Years.Psychology, 4, 994-997. doi: 10.4236/psych.2013.412143.

Dooley, D., \& Catalano, R. (1979). Economic, life, and disorder changes: Time-series analyses. American Journal of Community Psychology, 7(4), 381-396. doi:10.1007/bf00894381

Ellison, C. (1991). Religious Involvement and Subjective Well-Being.Journal of Health and Social Behavior, 32(1), 80-99. Retrieved from http://www.jstor.org/stable/2136801

Ellison, C., \& Lee, J. (2010). Spiritual Struggles and Psychological Distress: Is There a Dark Side of Religion? Social Indicators Research, 98(3), 501-517. Retrieved from http://www.jstor.org/stable/40800984

Field, A. (2013). Discovering statistics using IBM SPSS Statistics.S.I. Sage Publications.

Freud, S., Strachey, J., \& Gay, P. (1989).The future of an illusion. New York: Norton.

Galek, K., Krause, N., Ellison, C. G., Kudler, T., \& Flannelly, K. (2007). Religious doubt and mental health across the lifespan.Journal of Adult Development, 14(1), 16-25. doi:10.1007/s10804-007-9027-2

Gallup, G., Jr., \& Lindsay, D. M. (1999).Surveying the religious landscape: Trends in U.S. beliefs. Harrisburg, PA: Morehouse

Hackney, C. H., \& Sanders, G. S. (2003). Religiosity and Mental Health: A Meta-Analysis of Recent Studies. Journal for the Scientific Study of Religion, 42(1), 43-55. doi:10.1111/1468-5906.t01-1-00160 
Handal, P. J., \& Lace, J. W. (in press). Differential effects of family structure on religion and spirituality in emerging adult males and females. Journal of Religion and Health.doi:10.1007/s10943-016-0343-3

Handal, P. J., Gist, D., Gilner, F. H., \&Searight, H. R. (1993).Preliminary validity for the Langner symptom survey and the brief symptom inventory as mass-screening instruments for adolescent adjustment.Journal of Clinical Child Psychology, 22(3), 382-386. doi:10.1207/s15374424jccp2203_9

Handal, P. J., Peri, A., \&Pashak, T. J. (2014).Calibration of the Langner symptom survey for the college population.Current Psychology, 34(2), 389-400. doi:10.1007/s12144-0149264-z

Habibzadeh, F. (2013). Common statistical mistakes in manuscripts submitted to biomedical journals. European Science Editing, 39(4), 92-94.

Hunsberger, B., McKenzie, B., Pratt, M., \&Pancer, S. M. (1993). Religious doubt: A social psychological analysis. Research in the social scientific study of religion, 5, 27-51.

Hunsberger B.S., Pratt M., Pancer S.M. (2002). A longitudinal study of religious doubt in high school and beyond: Relationships, stability, and searching for answers. Journal for the Scientific Study of Religion, 41, 255-266.

Idler, E. L. (1987). Religious Involvement and the Health of the Elderly: Some Hypotheses and an Initial Test. Social Forces, 66(1), 226. doi:10.2307/2578909

Kapleau, P. (1980). The three pillars of Zen: teaching, practice, and enlightenment. Garden City, NY: Anchor Press.

Kézdy, A., Martos, T., Boland, V., \&Horváth-Szabó, K. (2011). Religious doubts and mental health in adolescence and young adulthood: The association with religious attitudes. Journal of Adolescence, 34(1), 39-47. doi:10.1016/j.adolescence.2010.03.003

Klaassen, D. W., \& McDonald, M. J. (2002). Quest and Identity Development: Re-Examining Pathways for Existential Search. International Journal for the Psychology of Religion, 12(3), 189-200. doi:10.1207/s15327582ijpr1203_05

Koenig, H. G. (2004). Religion, Spirituality, and Medicine: Research Findings and Implications for Clinical Practice. Southern Medical Journal, 97(12), 1194-1200. doi:10.1097/01.smj.0000146489.21837.ce

Koenig, H. G. (2012). Religion, Spirituality, and Health: The Research and Clinical Implications. ISRN Psychiatry, 2012, 1-33. doi:10.5402/2012/278730

Koenig, H. G., King, D. E., \& Carson, V. B. (2012).Handbook of religion and health. Oxford: Oxford University Press.

Krause, N. (2006). Religious Doubt and Psychological Well-Being: A Longitudinal Investigation. Review of Religious Research, 47(3), 287-302. Retrieved from http://www.jstor.org/stable/3512359

Krause, N., \&Wulff, K. (2004). Religious Doubt and Health: Exploring the Potential Dark Side of Religion. Sociology of Religion, 65(1), 35-56. Retrieved from http://www.jstor.org/stable/3712506

Krause, N., Ingersoll-Dayton, B., Ellison, C. G., \&Wulff, K. M. (1999).Aging, religious doubt, and psychological well-being.Gerontologist, 39(5), 525-533. 
Langner, T. S. (1962). A 22-item screening score of psychiatric symptoms indicating impairment. Journal of Health and Human Behavior, 3, 269-276. doi:10.2307/2948599

Lipsmeyer, M. E. (1984). The measurement of religiosity and its relationship to mental health/impairment (Unpublished doctoral dissertation).Saint Louis University, St. Louis, MO.

Mosher, J. P., \&Handal, P. J. (1997).The relationship between religion and psychological distress in adolescents.Journal of Psychology and Theology, 25(4), 449-457.

Ross, K., Handal, P. J., Clark, E. M., \& Vander Wal, J. S. (2009). The relationship between religion and religious coping: Religious coping as a moderator between religion and adjustment. Journal of Religion and Health, 48(4), 454-467. doi:10.1007/s10943-0089199-5

Schnabel, L. (2015). How religious are American women and men? Gender differences and similarities.Journal for the Scientific Study of Religion, 54(3), 616-622.

Schulenberg J.E. \&Zarrett N.R. (2006). Mental health during emerging adulthood: Continuity and discontinuity in courses, causes, and functions. In J.J. Arnett \& J.L. Tanner (Eds.), Emerging adults in America: Coming of age in the 21st century (pp. 135-72). Washington DC: American Psychological Association

Tillich, P. (2001). Dynamics of faith. New York: Perennial.

Watson, P. J., Morris, R. J., Hood, R. W., Milliron, J. T., \& Stutz, N. L. (1998). Religious Orientation, Identity, and the Quest for Meaning in Ethics Within an Ideological Surround. International Journal for the Psychology of Religion, 8(3), 149-164. doi:10.1207/s15327582ijpr0803_1

Weber, S. R., \&Pargament, K. I. (2014).The role of religion and spirituality in mental health.Current Opinion in Psychiatry, 27(5), 358-363. doi:10.1097/yco.0000000000000080

Zivin, K., Eisenberg, D., Gollust, S. E., \&Golberstein, E. (2009). Persistence of mental health problems and needs in a college student population. Journal of affective disorders, 117(3), 180-185. 